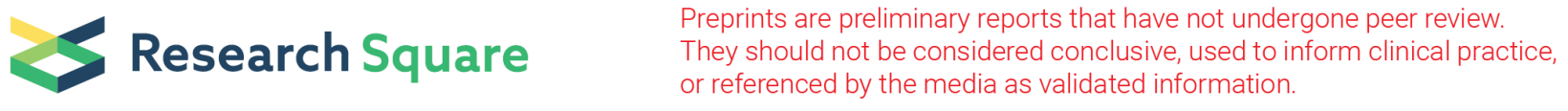

\title{
A Questionnaire Based on A Sub-Regional Hierarchical Level Showed the Following: Application of Medical Accident Insurance is Suitable in Shanghai, China
}

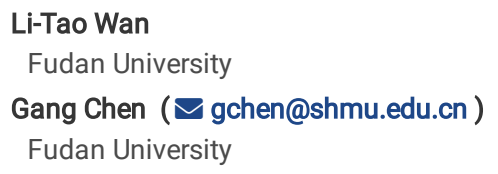




\section{Abstract}

Background: The application of medical accident insurance could not only cover parts of patients' property loss caused by non-medical negligence, but also reduce the risks of medical staff during medical services. However, the compensation mechanism for medical accidents is unsound in china.

Methods: In order to figure out the awareness and acceptance of the medical accident insurance in Shanghai medical institutions, medical staff and patients, a questionnaire survey was conducted. The feedback, which in total came from 22 medical institutions, 1,689 medical staff and 1,342 patients, was statistically analyzed by chi-square test.

Results囚Only $22.72 \%$ of the 22 hospitals in this questionnaire survey purchased medical accident insurance. As a result, medical accident insurance only accounts for $3.13 \%$ of medical compensation, which was far lower than the negotiated compensation ratio (61.25\%) and the medical liability insurance compensation ratio (14.38\%). This may be due to the low awareness of medical accident insurance, and our survey also proves this phenomenon. In this survey, we find that only a small proportion $(22.73 \%)$ of medical institutions purchase medical accident insurance. What is more unexpected is that the vast majorities of patients (50.00\%) and medical workers (64.00\%) have only heard of it and are not aware of it. Although nearly half of the patients (45.16\%) and medical workers (58.26\%) are willing to buy medical accident insurance, there were still some patients and medical workers who were uncertain (32.80\% and $38.82 \%$, respectively) or unwilling to buy it ( $8.94 \%$ and $16.02 \%$, respectively). The reason is nothing more than that no benefits will occur while the cost is high. Among those willing to buy, the majority of the patients (58.19\%) and medical workers $(54.39 \%)$ only accept the amount of insurance less than RMB 200 yuan.

Conclusions: The acceptability and cognition of medical accident insurance in medical workers and patients are still at a low level in Shanghai. In addition, preliminary data from medical institutions purchasing medical accident insurance shows that the insurance can effectively reduce medical disputes and ease economic burden. To sum up, medical accident insurance has good application prospect and space in Shanghai, China.

\section{Background}

Medicine is a high-risk practical science, because it usually combines with unpredicting and unpreventable medical accidents, the causes of which are very complex while the consequences are harmfully. The losses caused by medical accidents, including physical injures and economic depletion, patients and their families are difficult to face and bear, which would result in a strong emotional stress of patients as well as their family members[1,2]. Eventually, the explanation of medical staff was unacceptable and the conflicts between doctors and patients would become more and more deteriorated[3]. Therefore,to decrease the losses and adverse social consequences caused by medical accidents, the current risk sharing mode in China is an insurance mechanism, which is also widely adopted by the international community[4]. In the current practice of China, the majority of medical insurance claims are only provided for injuries caused by medical fault, that is, medical liability insurance. However, only about $40 \%$ of medical disputes could be put down to medical liability [5, 6]. A considerable proportion of medical disputes can't be attributed to the responsibility of the medical party, which in most cases belongs to the medical accident [7, 8]. In fact, people understanding of medicine is also the tip of the iceberg, as Dr Trudeau said: To Cure Sometimes, To Relieve Often, To Comfort Always[9].

How to solve the medical accidental losses caused by a large proportion of non-medical faults during the medical therapeutic process has become an urgent problem in China. A complete medical risk insurance system shouldn't only include the medical liability insurance, should also include the medical accident insurance and medical personnel practice insurance[10]. Although the Chinese law has always encouraged the establishment of medical accident insurance, it is still blank or at the exploring stage in the most regions of China[11]. In China, voluntary or semi-compulsory insurance has been implemented in the transportation, tourism and other industries. For example, a certain amount of basic accident insurance is provided along with train or airline tickets. In addition, advanced accident insurance products with comprehensive insurance coverage are also provided to choose. The accident risk in the medical industry is not lower than that in the above-mentioned industries[12], therefore a corresponding medical accident insurance system should also be established, which could not only compensate the suffering of patients and their family from medical accident in time and provide economic basis for the follow-up treatment and rehabilitation,but also effectively alleviate the conflicts between doctors and patients[13].

As the largest and most developed city, Shanghai has most advanced medical resource, however, it is also the city with the largest number of medical accidents, which caused the high rate of doctor-patient disputes in China[14]. How to resolve the harmful consequences for both side of medical staff and patients and achieve medical safety by the establishment of constructing and perfecting insurance mechanism has become an important topic for the health administration departments and local governments. This paper intends to investigate the understanding and acceptance of medical accident insurance from 1689 medical managers and staff as well as 1342 patients in 22 secondary and above medical institutions, which may provide decision-making basis for the implementation of medical accident insurance policy in the next step.

\section{Methods \\ Samples and data collection}

This research is a data analysis research based on one stratified online questionnaire survey, which is mainly to investigate the cognition and attitude of related groups in the hospital towards medical accident insurance. The medical managers and staff as well as the corresponding patients from 22 secondary Grade and above medical institutions distributed in different regions of Shanghai were involved in the related groups and participated in our questionnaire survey. The study protocol was carried out in accordance with relevant guidelines and regulations. 
The data on medical accident insurance from 1689 medical staff and 1342 patients were obtained. These data include the characteristics of the hospital (the hospital's location, level and accident insurance purchases), the demographic characteristics of the survey respondents (the gender, age, education, job title, per capita annual income, and department of the medical staff and patients), as well as the cognition and attitude of the relevant population towards the medical accident insurance (whether understand medical accident insurance, whether willing to purchase it, acceptable premiums, and the reasons why unwilling to purchase it.). The flow charts were described in Fig. 1.

\section{Data analysis}

Statistical analysis was performed by chi-square test using SPSS18.0 software between different groups. Pie chart and histogram were made by GraphPad Prism 5 software. $P$ value $<0.05$ was considered statistically significant.

\section{Results}

\section{Samples distributionin this questionnaire survey}

To better understand the current doctor-patient relationship and the mechanisms by which hospitals respond to medical incidents, 22 medical institutions in Shanghai were randomly selected to conduct a questionnaire survey. Of which, 10 were secondary hospitals and 12 were tertiary hospitals (table.1). As shown in table 1, 22 hospitals were distributed in different regions of Shanghai, including 8 hospitals from urban, 10 from suburb and 4 from suburban combination. Meanwhile, in this questionnaire survey, we selected 1689 medical staff and 1342 patients to conduct questionnaires among different groups (table.1).

\section{Investigation on the occurrence of medical malpractice and the way of compensation}

Following, we did a survey on the current situation of medical disputes in those 22 hospitals. The results of the questionnaire survey showed that $9.47 \%$ of the surveyed medical staff had personally experienced medical disputes (Fig.2A). As for medical accidents, 3.61\% of medical staff had ever had one (Fig.2B). In case a medical accident happens, the main way of compensation is the negotiation between doctor and patient, accounting for $61.24 \%$, followed by the medical liability insurance, accounting for $14.38 \%$. Surprisingly, only $3.13 \%$ of the compensation events were covered by medical accident insurance (Fig. 2 C).

\section{Investigation on the purchase of medical accident insurance}

In view of the low proportion of medical accident insurance in medical accident compensation, we investigated the purchase of medical accident insurance in 22 hospitals. The results revealed that only five (22.73\%) institutions had purchased medical accident insurance among the 22 hospitals surveyed in this survey (Fig.3A). Regarding the insured, two (40.00\%) of them covered all employees of the hospitals, two (40.00\%) covered only medical staff, and one (20.00\%) covered only nurses (Fig.3B). As for the source of insurance premiums, three $(60.00 \%)$ of them were borne by the hospital and medical staff in a certain proportion, one (20.00\%) was borne by the hospital, and the other $(20.00 \%)$ was borne by the medical staff (Fig.3C). Among the institution not purchasing medical accident insurance, 10 were willing to purchase in the future. Among them, five (50.00\%) were willing to cover all medical staff, three (30.00\%) were willing to cover only the medical staff in high-risk departments, and two (20.00\%) were willing to cover all employees in the hospital (Fig.3D). In terms of the source of funds, five hospitals (50.00\%) thought that the hospital and medical staff could share in a certain proportion, three hospitals (30.00\%) thought that both doctors and patients could share in a certain proportion, one hospital $(10.00 \%)$ hoped that the medical staff would bear it personally and one hospital (10.00\%) thought that the patients would bear it personally (Fig.3E). From the perspective of the benefits rooting in promoting and implementing of medical accident insurance, 15 hospitals believed that medical accident insurance could help to reduce medical disputes, 14 hospitals believed that medical accident insurance could help to guide patients to carefully choose treatment methods, and 11 believed that the financial risks caused by surgical accidents could be transferred (Fig.3F).

\section{Investigation on cognition of medical accident insurance}

From the above survey, we knew that the rate of the purchase and application of medical accident insurance was very low under the existing circumstances. Therefore, we conducted another survey on the attitude of the doctor-patient relationship and the cognition of medical accident insurance among medical staff and patients.

For the doctor-patient relationship, a small number (24.63\%) of medical workers thought that it was very harmonious, nearly half of them think it is relatively harmonious, accounting for $48.02 \%$, and $20.67 \%$ thought it was tense (Fig.4A). However, in patients, the vast majority thought that the doctor-patient relationship was harmonious, accounting for $77.87 \%$, and only $1.94 \%$ of the patients thought that it was disharmonious (Fig. $4 \mathrm{~A}$ ). In the hierarchical analysis of demography, statistical significance $(P<0.05 \llbracket$ were presented between cognition of doctor-patient relationship and most parameters, such as age, education background, professional title and department of the medical staff, whether in medical staff or patients (table 2).

Regarding the degree in understanding the medical accident insurance, only $21.85 \%$ of the medical staff knew it, $64.00 \%$ heard of it only without knowing the specifics, and $14.15 \%$ had never heard of it. Among patients, the proportion of patients who understand medical accident insurance was slightly higher than that of medical staff, accounting for 33.98\% (Fig.4B). In addition, there was a statistical significance in the perceptions of medical accident insurance between medical staff and patients $(P<0.001)$. In the hierarchical analysis of demography, statistical significance $(P<0.05 \rrbracket$ were presented between the degree of understanding the medical accident insurance and merely some parameters, such as gender, age and professional title in medical staff, as well as hospital area, education background and annual per capita income in patients (table 3).

Subsequently, we analyzed the willingness of people to purchase medical accident insurance in both medical staff and patients. The results showed that $58.26 \%$ of medical staff was willing to buy, $32.80 \%$ were uncertain, and $8.94 \%$ were unwilling to buy (Fig. 4 C). Among those who were unwilling to buy, $37.75 \%$ 
thought that it was of little significance to alleviate medical disputes, $33.77 \%$ had no purchase awareness, and $18.54 \%$ thought that the cost was too high (Fig.4D). Among the patients, $45.16 \%$ were willing to buy, $16.02 \%$ were unwilling, and $38.82 \%$ were not sure whether to buy (Fig.4C). Among the patients who were unwilling to purchase, $36.74 \%$ had no purchase awareness, $20.00 \%$ said that there were not many actual benefits to them after purchasing, and not knowing how to buy and thinking that the cost is too high accounted for $17.21 \%$, respectively (Fig.4D). In addition, there was a statistical significance in the willingness of people to purchase medical accident insurance between medical staff and patients $(P<0.001)$. In the hierarchical analysis of demography, statistical significance $(P<0.05 \rrbracket$ were presented between the willingness of people to purchase medical accident insurance and most parameters, such as gender, age, education background, professional title / annual per capita income and department of the medical staff, whether in medical staff or patients (table 4).

As some respondents thought that the purchase cost of medical accident insurance was too high, we set five levels of payment amount and analyzed their acceptance. The results showed that $30.75 \%$ accepted below 100 yuan, $27.44 \%$ accepted $100-200$ yuan, $16.38 \%$ accepted $200-300$ yuan, $15.02 \%$ accepted $300-500$ yuan, and $10.40 \%$ accepted 500 yuan or more among medical workers (Fig.4E). In patients, it was similar to medical staff, accounting for $27.42 \%$, $26.97 \%, 15.71 \%, 17.13 \%, 12.78 \%$ respectively (Fig.4E). Hence, no statistical significance was established in the amount of contributions acceptable for medical accident insurance between medical staff and patients $(P=0.102)$. In the hierarchical analysis of demography, statistical significance $(P<0.05 \llbracket$ were presented between the amount of contributions acceptable for medical accident insurance and some parameters, such as gender, education background and professional title in medical staff, as well as hospital area, education background and annual per capita income in patients (table5).

\section{Discussion}

\section{Medical accidents are objective and prone to serious consequences}

Medical accident represents an objective adverse consequence, which is caused by current limitations of medicine technology and some unpredictable and unpreventable status of patients' body or disease[10,15]. At the same time, medicine science is a sophisticated discipline that integrates check-up, diagnosis, therapy, and recovery, which combins with multivariate and complex uncertain factors[16]. Therefore, the reasons causing medical accidents could be pathological, psychological and environmental factors, individual differences in patients, side effects of medication and surgical treatment, restrictions on the level of medical development, clinical experience of medical staff, and so on[17]. Because of these reasons, it is not surprising that medical accidents are still difficult to be predicted and prevented, even under mature and advanced diagnosis and treatment technology in the future.

The direct adverse consequences of medical accidents usually are physical injures of patients and different degrees of economic losses. However, serious medical accidents would further tend to result in psychological pressures for both patients and their family members[17]. Importantly, no matter direct or indirect consequences of medical accidents, both are hard to be accepted and born by patients and their families, particularly when they were explained there was no direct fault and responsibility of medical staff, which in fact really happened within medical accidents[18, 19]. As a result, in order to get compensation, the patients can only emphasize the fault of the medical behaviors and, which leads to the deterioration of the doctor-patient relationship. To sum up, it is urgent to build up one high-efficiency compensation mechanism for medical accidents in China, which could protect corresponding patients and medical staff without medical negligence, and greatly ease the contradiction between doctors and patients[20].

\section{The applications of insurance mechanism of medical accidents worldwide}

Insurance has an extraordinary meaning to resolve and resist risks. The development of medical insurance, such as medical accident insurance, not only satisfies with demands of the medical and insurance markets, but also meets the needs of social development. Using of medical accident insurance could largely bear the economic losses caused by medical accidents[21]. In addition, the promulgation of relevant laws has provided a legal basis for handling medical accidents. In 1972, New Zealand promulgated an accident compensation law, which stipulates that patients suffering medical accidents could obtain compensation from the accident compensation committee established by the state without the need to sue the court or the tort liability law[22]. Sweden established the patient compensation insurance system in 1975[23]. In this system, if patients suffered injure while seeking medical care in a public hospital, the insurance would compensate the patient regardless of the negligence of the medical personnel or the medical institution. In 2002, France promulgated the "Patient Rights and Health System Quality Law", stipulating medical accidents caused by pure medical risks, such as nosocomial infections, no-fault blood transfusions, anesthesia accidents, etc., are compensated by the medical accident compensation fund established by the state[24] [1].

However, in China, no unified medical accident compensation system has yet been formed guided by the nation, even in the medical accident insurance industry itself [20]. It was exciting that somewhere in China had made preliminary attempts to provide financial assistance for no-fault medical malpractice. Such as, Zhenjiang municipal government of Jiangsu Province had passed the "no fault medical damage relief measures of Zhenjiang City" in 2014, which stipulated that a certain amount of economic assistance would be given to patients who suffered serious consequences of medical accidents [25]. This was the first no fault medical injure relief system funded by local government in China, but it was not to adopt insurance mechanism and has no sustainability

\section{It is difficult for policies and laws to fundamentally promote the development of medical accident insurance}

The establishment of medical accident insurance system would free the medical institutions from complicated medical disputes and avoid paying huge compensation, which could concentrate their energy and financial resources promoting the healthy development of medical and health services[26]. On the other hand, patients suffered medical accidents could be provided material basis for the follow-up treatment and recovery via insurance compensation, which would effectively alleviate the contradiction between doctors and patients[27]. In view of this, a number of policies have been successively formulated by the state. For example, the "Regulations on the Prevention and Treatment of Medical Disputes" and "Measures for the Protection of the Rights and Interests of Medical and Health Personnel in Shanghai" respectively implemented in 2018 and 2021 both have provisions in the medical risk sharing clauses, which encourage patients to participate in medical accident insurance[20,28]. However, there is still no supporting implementation strategy to carry out these 
existing policies and laws in China. Therefore, medical accident insurance products have not fully entered into medical institutions and the original intention of guaranteeing medical accident is difficult to be fulfilled. Medical insurance which should have been popular is difficult to popularize.

In the present survey, only a few hospitals believe that medical accident insurance contribute to reduce medical disputes and alleviate the financial risks caused by medical accidents. The majority of the medical staff and patients involved in this questionnaire survey do not fundamentally realize the role and significance of medical accident insurance in handling medical accidents. In addition, the propaganda and popularization of medical accident insurance was underestimated by the hospital and patients. Therefore, what urgently needs to be solved in the next step is to increase the publicity and the awareness of medical accident insurance among medical staff and patients, which would help to understand the role and importance of medical accident insurance, thus promoting medical safety and building doctor-patient harmony.

Meanwhile, the development model of medical accident insurance is still in the exploratory stage. In view of this, the inclusive medical insurance productsHuHuiBao, an exclusive inclusive commercial supplementary health insurance for the public, launched in Shanghai in $2021 \rrbracket$ which can be used as a reference. It is specially developed for Shanghai Medical Insurance participants, and the government departments unify the premium standard, treatment standard and coverage, in order to meet the multi-level medical needs of citizens and realize the effective connection between social medical insurance and commercial health insurance. As a supplement to medical liability insurance, medical accident insurance can reduce the loss which is not due to the medical negligence. It can be linked to medical liability insurance through effective guidance and active promotion by the government, which can benefit all patients and improve the medical risk sharing mechanism.

\section{Conclusions}

This research is carried out for the first time in the form of a questionnaire in diverse regions and hierarchies, which finds out that the acceptability and the cognition of medical accident insurance in medical workers and patients are still at a low level in Shanghai. Hence, it is necessary to strengthen the publicity of medical accident insurance, expand people's cognition of medical accident insurance, and make it better serve for the medical cause. In addition, preliminary data from medical institutions purchasing medical accident insurance shows that the insurance can effectively reduce medical disputes and ease economic burden. To sum up, medical accident insurance has good application prospect and space in Shanghai, China.

\section{Declarations}

\section{Ethics approval and consent to participate}

Ethics approval of the study protocol was granted by the Human Research Ethics Committee of Fudan University. The study protocol was carried out in accordance with relevant guidelines and regulations. All of the survey participants provided written informed consent prior to survey completion.

\section{Consent for publication}

Not Applicable

\section{Availability of data and material}

The data that support the findings of this study are available from the corresponding author, upon reasonable request.

\section{Competing interests}

All authors declare no conflicts of interest.

\section{Funding}

This work was supported by the Scientific Research Project of Shanghai Municipal Health and Family Planning Commission (NO. 201740250).

\section{Authors' contributions}

Both authors contributed to the study design. LW was responsible for data acquisition. GC analysed and interpreted the data. LW drafted the manuscript, and GC contributed to its revision. Both authors read and approved the final manuscript.

\section{Acknowledgements}

Not applicable.

\section{References}

1. Brennan TA, Leape LL, Laird NM, Hebert L, Localio AR, Lawthers AG, Newhouse JP, Weiler PC, Hiatt HH: Incidence of adverse events and negligence in hospitalized patients. Results of the Harvard Medical Practice Study I. N Engl J Med 1991, 324(6):370-376.

2. Medical malpractice litigation raises health-care cost, reduces access, and lowers quality of care. J Med Pract Manage 2004, 20(1):44-51.

3. Floyd TK: Medical malpractice: trends in litigation. Gastroenterology 2008, 134(7):1822-1825, 1825 e1821.

4. Van Koevering M: Medical liability reform moves to forefront of health care debates. Healthplan 2003, 44(2):8, 10. 
5. Liang F, Liu J, Zhou H, Liu P: Inequality in the last resort: how medical appraisal affects malpractice litigations in China. Int J Legal Med 2021, 135(3):1047-1054.

6. Papavramidou N, Voultsos P: Medical malpractice cases in Hippocratic collection: a review and today's perspective. Hippokratia 2019, 23(3):99-105.

7. Jha AK, Larizgoitia I, Audera-Lopez C, Prasopa-Plaizier N, Waters H, Bates DW: The global burden of unsafe medical care: analytic modelling of observational studies. BMJ Qual Saf 2013, 22(10):809-815.

8. Studdert DM, Brennan TA: No-fault compensation for medical injuries: the prospect for error prevention. JAMA 2001, 286(2):217-223.

9. Gordon J: Medical humanities: to cure sometimes, to relieve often, to comfort always. Med J Aust 2005, 182(1):5-8.

10. Rodziewicz TL, Houseman B, Hipskind JE: Medical Error Reduction and Prevention. In: StatPearls. edn. Treasure Island (FL); 2021.

11. Li Y, Lu C, Liu Y: Medical Insurance Information Systems in China: Mixed Methods Study. JMIR Med Inform 2020, 8(9):e18780.

12. Kuhn T: Medical risk assessment in personal life insurance, disability insurance and accident insurance. MMW Fortschr Med 2010,151 Suppl 4:169-172.

13. Wallis K: New Zealand's 2005 'no-fault' compensation reforms and medical professional accountability for harm. NZ Med J 2013, 126(1371):33-44.

14. Jiang Y, Ying X, Zhang Q, Tang SR, Kane S, Mukhopadhyay M, Qian X, authorship Ht: Managing patient complaints in China: a qualitative study in Shanghai. BMJ Open 2014, 4(8):e005131.

15. Friedman SM, Provan D, Moore S, Hanneman K: Errors, near misses and adverse events in the emergency department: what can patients tell us? CJEM 2008, 10(5):421-427.

16. Panda SC: Medicine: science or art? Mens Sana Monogr 2006, 4(1):127-138.

17. Bari A, Khan RA, Rathore AW: Medical errors; causes, consequences, emotional response and resulting behavioral change. Pak J Med Sci 2016 , 32(3):523-528.

18. Hodgson J: Medical malpractice: an overview of the English position. Ann Health Law 1994, 3:225-242.

19. Bal BS: An introduction to medical malpractice in the United States. Clin Orthop Relat Res 2009, 467(2):339-347.

20. Wang M, Liu GG, Zhao H, Butt T, Yang M, Cui Y: The role of mediation in solving medical disputes in China. BMC Health Serv Res 2020, 20 (1):225.

21. Kessler DP: Evaluating the medical malpractice system and options for reform. J Econ Perspect 2011, 25(2):93-110.

22. Connell S: Community insurance versus compulsory insurance: Competing paradigms of no-fault accident compensation in New Zealand. Legal Studies 2019, 39(3):499-516.

23. Johansson H: The Swedish system for compensation of patient injuries. Ups J Med Sci 2010, 115(2):88-90.

24. Brennan F, Carr DB, Cousins M: Pain management: a fundamental human right. Anesth Analg 2007, 105(1):205-221.

25. Zhang Y, Wang Q, Jiang T, Wang J: Equity and efficiency of primary health care resource allocation in mainland China. Int $J$ Equity Health 2018 , 17(1):140.

26. Wu TY, Majeed A, Kuo KN: An overview of the healthcare system in Taiwan. London J Prim Care (Abingdon) 2010, 3(2):115-119.

27. Pandit MS, Pandit S: Medical negligence: Coverage of the profession, duties, ethics, case law, and enlightened defense - A legal perspective. Indian J Urol 2009, 25(3):372-378

28. Ding J, Fu H, Liu Y, Gao J, Li Z, Zhao X, Zheng J, Sun W, Ni H, Ma X et al: Prevention and control measures in radiology department for CoVID-19. Eur Radiol 2020, 30(7):3603-3608.

\section{Tables}

Table 1. Distribution of hospitals participated in the survey in Shanghai

\begin{tabular}{|c|c|c|c|c|c|c|c|}
\hline \multirow[t]{3}{*}{ Parameter } & & \multirow{2}{*}{\multicolumn{2}{|c|}{ Hospital }} & \multicolumn{4}{|c|}{ Interviewee } \\
\hline & & & & \multicolumn{2}{|c|}{ Medical staff } & \multicolumn{2}{|c|}{ Patient } \\
\hline & & $\mathrm{N}$ & $\%$ & $\mathrm{~N}$ & $\%$ & $\mathrm{~N}$ & $\%$ \\
\hline \multirow[t]{2}{*}{ Hospital grade } & III & 12 & 54.55 & 932 & 55.18 & 806 & 60.06 \\
\hline & ॥ & 10 & 45.45 & 757 & 44.82 & 536 & 39.94 \\
\hline \multirow[t]{3}{*}{ Area } & urban & 8 & 36.37 & 769 & 45.53 & 716 & 53.35 \\
\hline & Suburb & 10 & 45.45 & 790 & 46.77 & 519 & 38.68 \\
\hline & Suburban combination & 4 & 18.18 & 130 & 7.70 & 107 & 7.97 \\
\hline Total & & 22 & 100 & 1689 & 100 & 1342 & 100 \\
\hline
\end{tabular}

Table 2. Attitudes towards the doctor-patient relationship between medical staff and patient 


\begin{tabular}{|c|c|c|c|c|c|c|c|c|c|c|}
\hline \multirow[t]{3}{*}{ parameter } & \multicolumn{4}{|c|}{ Medical staff } & \multirow[t]{2}{*}{ statistics } & \multicolumn{4}{|l|}{ Patient } & \multirow[t]{3}{*}{ statisti } \\
\hline & Harmony & General & Disharmony & Unclear & & Harmony & General & Disharmony & Unclear & \\
\hline & $N(\%)$ & $\mathrm{N}(\%)$ & $\mathrm{N}(\%)$ & $\mathrm{N}(\%)$ & & $\mathrm{N}(\%)$ & $\mathrm{N}(\%)$ & $\mathrm{N}(\%)$ & $\mathrm{N}(\%)$ & \\
\hline \multicolumn{11}{|l|}{ Area } \\
\hline $\begin{array}{l}\text { suburban } \\
\text { combination }\end{array}$ & $26(20.00)$ & $63(48.46)$ & $31(23.85)$ & 10(7.69) & $\chi^{2}=16.715$ & 79(73.83) & $26(24.30)$ & $1(0.93)$ & $1(0.93)$ & $\chi^{2}=3.3$ \\
\hline suburb & $170(21.52)$ & $383(48.48)$ & 181(22.91) & $56(7.09)$ & $P=0.033$ & 412(79.38) & 91(17.53) & 11(2.12) & $5(0.96)$ & $P=0.7 \epsilon$ \\
\hline urban & $220(28.61)$ & $365(47.46)$ & 137(17.81) & $47(6.11)$ & & 554(77.37) & 141(19.69) & 14(1.96) & 7(0.98) & \\
\hline \multicolumn{11}{|l|}{ Gender } \\
\hline male & 71(17.75) & $183(45.75)$ & 127(31.75) & 19(4.75) & $\chi^{2}=45.276$ & $388(80.33)$ & $86(17.81)$ & 6(1.24) & $3(0.62)$ & $\chi^{2}=4.2$ \\
\hline female & $345(26.76)$ & $628(48.72)$ & 222(17.22) & $94(7.29)$ & $P<0.001$ & 657(76.48) & 172(20.02) & $20(2.33)$ & $10(1.16)$ & $P=0.2 \angle$ \\
\hline \multicolumn{11}{|l|}{ Age } \\
\hline $18-30$ & 124(38.39) & 150(46.44) & $32(9.91)$ & $17(5.26)$ & $\chi^{2}=87.621$ & 211(72.76) & 71(24.48) & $5(1.72)$ & $3(1.03)$ & $\chi^{2}=23$. \\
\hline $31-45$ & $181(24.04)$ & $381(50.60)$ & 137(18.19) & $54(7.17)$ & $P<0.001$ & 519(77.69) & 124(18.56) & $19(2.84)$ & $6(0.91)$ & $P=0.02$ \\
\hline $46-60$ & 80(19.09) & 193(46.06) & 122(29.11) & $24(5.73)$ & & 148(79.14) & 36(19.25) & $2(1.07)$ & $1(0.53)$ & \\
\hline$>61$ & $31(15.98)$ & $87(44.85)$ & $58(29.90)$ & 189.28) & & 167(84.77) & $27(13.71)$ & $0(0.00)$ & $3(1.52)$ & \\
\hline \multicolumn{11}{|l|}{ Education } \\
\hline postgraduate & $56(16.47)$ & $165(48.53)$ & $97(28.53)$ & $22(6.47)$ & $\chi^{2}=60.312$ & 41(70.69) & $12(20.69)$ & $5(8.62)$ & $0(0.00)$ & $\chi^{2}=46$ \\
\hline undergraduate & $186(22.55)$ & 402(48.73) & $183(22.18)$ & $54(6.55)$ & $P<0.001$ & 471(72.35) & 157(24.12) & $16(2.46)$ & $7(1.08)$ & $P<0.0$ \\
\hline $\begin{array}{l}\text { short-cycle } \\
\text { Courses }\end{array}$ & 163(33.33) & $226(46.22)$ & 67(13.70) & $33(6.75)$ & & 263(80.92) & $55(16.92)$ & $3(0.92)$ & $4(1.23)$ & \\
\hline $\begin{array}{l}\text { short-cycle } \\
\text { Courses and } \\
\text { Under }\end{array}$ & 11(31.43) & $18(51.43)$ & $2(5.71)$ & $4(11.43)$ & & $270(87.66)$ & $34(11.04)$ & $2(0.65)$ & $2(0.65)$ & \\
\hline \multicolumn{11}{|l|}{ Title*/Income } \\
\hline professor/> 10 & $4(18.18)$ & $11(50.00)$ & $6(27.27)$ & $1(4.55)$ & $\chi^{2}=102.767$ & 173(74.89) & 49(21.21) & $9(3.90)$ & $0(0.00)$ & $\chi^{2}=23$. \\
\hline $\begin{array}{l}\text { associate } \\
\text { professor /5.1- } \\
10\end{array}$ & 15(12.61) & $46(38.66)$ & 46(38.65) & $12(10.08)$ & $P<0.001$ & $341(76.12)$ & $97(21.65)$ & $5(1.12)$ & $5(1.12)$ & $P=0.02$ \\
\hline $\begin{array}{l}\text { middle title } \\
\text { /3.1-5 }\end{array}$ & $99(18.00)$ & 258(46.91) & 155(28.18) & $38(6.91)$ & & 245(82.49) & 45(15.15) & $3(1.01)$ & $4(1.35)$ & \\
\hline primary/1.1-3 & $214(28.19)$ & $377(49.67)$ & $122(16.08)$ & $46(6.06)$ & & 155(83.33) & $27(14.52)$ & $3(1.61)$ & $1(0.54)$ & \\
\hline no title/0-1 & $84(35.15)$ & 119(49.79) & $20(8.37)$ & $16(6.69)$ & & 131(72.78) & $40(22.22)$ & 6(3.33) & $3(1.67)$ & \\
\hline \multicolumn{11}{|l|}{ Departments } \\
\hline $\begin{array}{l}\text { obstetrics- } \\
\text { Gynecology }\end{array}$ & $98(21.12)$ & 226(48.71) & $104(22.41)$ & $36(7.76)$ & $\chi^{2}=31.197$ & 242(77.32) & 63(20.13) & $5(1.60)$ & $3(0.96)$ & $\chi^{2}=18$ \\
\hline orthopedics & $60(22.22)$ & 131(48.52) & $66(24.45)$ & $13(4.81)$ & $P=0.013$ & 203(77.19) & $54(20.53)$ & $3(1.14)$ & $3(1.14)$ & $P=0.11$ \\
\hline General surgery & $132(25.34)$ & $249(47.79)$ & 107(20.54) & $33(6.33)$ & & $321(74.31)$ & $93(21.53)$ & $13(3.01)$ & $5(1.16)$ & \\
\hline neurosurgery & 91(33.33) & $116(42.49)$ & $47(17.22)$ & $19(6.96)$ & & 163(84.02) & $30(15.46)$ & $0(0.00)$ & $1(0.52)$ & \\
\hline $\begin{array}{l}\text { Cardio- } \\
\text { Thoracic } \\
\text { Surgery }\end{array}$ & $35(21.74)$ & $89(55.28)$ & 25(15.53) & $12(7.45)$ & & 116(82.86) & $18(12.86)$ & $5(3.57)$ & $1(0.71)$ & \\
\hline Total & $416(24.63)$ & $811(48.02)$ & 349(20.66) & 113(6.69) & & 1045(77.87) & 258(19.23) & $26(1.94)$ & $13(0.97)$ & \\
\hline
\end{tabular}

* represent professional title in medical staff

**represent annual per capita income in patients

Table 3. Knowledge of medical accident insurance between medical staff and patient 


\begin{tabular}{|c|c|c|c|c|c|c|c|c|}
\hline \multirow[t]{3}{*}{ parameter } & \multicolumn{3}{|c|}{ Medical staff } & \multirow[t]{3}{*}{ statistics } & \multicolumn{3}{|l|}{ Patient } & \multirow[t]{3}{*}{ statistics } \\
\hline & Understand & Heard & Unknown & & Understand & Heard & Unknown & \\
\hline & $\mathrm{N}(\%)$ & $N(\%)$ & $\mathrm{N}(\%)$ & & $\mathrm{N}(\%)$ & $\mathrm{N}(\%)$ & $\mathrm{N}(\%)$ & \\
\hline \multicolumn{9}{|l|}{ Area } \\
\hline suburban combination & $32(24.62)$ & $79(60.77)$ & $19(14.62)$ & $\chi^{2}=2.279$ & $27(25.23)$ & $51(47.66)$ & $29(27.10)$ & $\chi^{2}=19.864$ \\
\hline suburb & 172(21.77) & $515(65.19)$ & 103(13.04) & $P=0.685$ & 158(30.44) & $283(54.53)$ & $78(15.03)$ & $P=0.001$ \\
\hline urban & $165(21.46)$ & 487(63.33) & $117(15.21)$ & & 271(37.85) & $337(47.07)$ & $108(15.08)$ & \\
\hline \multicolumn{9}{|l|}{ Gender } \\
\hline male & $94(23.50)$ & $272(68.00)$ & $34(8.50)$ & $\chi^{2}=13.79$ & 150(31.06) & $250(51.76)$ & $83(17.18)$ & $\chi^{2}=3.003$ \\
\hline female & $275(21.33)$ & $809(62.76)$ & $205(15.90)$ & $P=0.001$ & $306(35.62)$ & $421(49.01)$ & 132(15.37) & $P=0.223$ \\
\hline \multicolumn{9}{|l|}{ Age } \\
\hline $18-30$ & $76(23.53)$ & 197(60.99) & $50(15.48)$ & $\chi^{2}=17.521$ & $99(34.14)$ & $151(52.07)$ & $40(13.79)$ & $\chi^{2}=8.218$ \\
\hline $31-45$ & 140(18.59) & $488(64.81)$ & $125(16.60)$ & $P=0.008$ & $224(33.53)$ & $345(51.65)$ & $99(14.82)$ & $P=0.412$ \\
\hline $46-60$ & $107(25.54)$ & $271(64.68)$ & 41(9.79) & & $61(32.62)$ & $88(47.06)$ & $38(20.32)$ & \\
\hline$>61$ & $46(23.71)$ & $125(64.43)$ & $23(11.86)$ & & $72(36.55)$ & $87(44.16)$ & $38(19.29)$ & \\
\hline \multicolumn{9}{|l|}{ Education } \\
\hline postgraduate & $70(20.59)$ & 231(67.94) & $39(11.47)$ & $\chi^{2}=12.222$ & $28(48.28)$ & $25(43.10)$ & $5(8.62)$ & $\chi^{2}=25.23$ \\
\hline undergraduate & 166(20.12) & $543(65.82)$ & $116(14.06)$ & $P=0.142$ & 243(37.33) & $327(50.23)$ & $81(12.44)$ & $P<0.001$ \\
\hline short-cycle Courses & $123(25.15)$ & $289(59.10)$ & $77(15.75)$ & & $93(28.62)$ & 165(50.77) & $67(20.62)$ & \\
\hline short-cycle Courses and Under & $10(28.57)$ & $18(51.43)$ & $7(20.00)$ & & $92(29.87)$ & $154(50.00)$ & $62(20.13)$ & \\
\hline \multicolumn{9}{|l|}{ Title*/Income** } \\
\hline professor/> 10 & $8(36.36)$ & $13(59.09)$ & $1(4.55)$ & $\chi^{2}=16.427$ & $96(41.56)$ & $113(48.92)$ & $22(9.52)$ & $\chi^{2}=16.33$ \\
\hline associate professor /5.1-10 & $28(23.53)$ & 79(66.39) & $12(10.08)$ & $P=0.037$ & 149(33.26) & $225(50.22)$ & $74(16.52)$ & $P=0.038$ \\
\hline middle title /3.1-5 & $130(23.64)$ & $360(65.45)$ & $60(10.91)$ & & $97(32.66)$ & 149(50.17) & $51(17.17)$ & \\
\hline primary/1.1-3 & 151(19.89) & $483(63.64)$ & $125(16.47)$ & & $55(29.57)$ & $90(48.39)$ & $41(22.04)$ & \\
\hline no title/0-1 & $52(21.76)$ & $146(61.09)$ & $41(17.15)$ & & $59(32.78)$ & $94(52.22)$ & $27(15.00)$ & \\
\hline \multicolumn{9}{|l|}{ Departments } \\
\hline obstetrics-Gynecology & $84(18.10)$ & $310(66.81)$ & $70(15.09)$ & $\chi^{2}=10.142$ & 108(34.50) & $145(46.33)$ & $60(19.17)$ & $\chi^{2}=11.919$ \\
\hline orthopedics & $62(22.96)$ & 179(66.30) & $29(10.74)$ & $P=0.255$ & 102(38.78) & $127(48.29)$ & $34(12.93)$ & $P=0.155$ \\
\hline General surgery & 113(21.69) & $331(63.53)$ & $77(14.78)$ & & 143(33.10) & $229(53.01)$ & $60(13.89)$ & \\
\hline neurosurgery & $70(25.64)$ & $164(60.07)$ & $39(14.29)$ & & $57(29.38)$ & 104(53.61) & $33(17.01)$ & \\
\hline Cardio-Thoracic Surgery & $40(24.84)$ & $97(60.25)$ & $24(14.91)$ & & $46(32.86)$ & $66(47.14)$ & $28(20.00)$ & \\
\hline Total & $369(21.85)$ & 1081(64.00) & $239(14.15)$ & & 456(33.98) & $671(50.00)$ & $215(16.02)$ & \\
\hline
\end{tabular}

* represent professional title in medical staff

**represent annual per capita income in patients

Table 4. Intention to purchase medical accident insurance between medical staff and patient 


\begin{tabular}{|c|c|c|c|c|c|c|c|c|}
\hline \multirow[t]{3}{*}{ parameter } & \multicolumn{3}{|l|}{ Medical staff } & \multirow[t]{3}{*}{ statistics } & \multicolumn{3}{|l|}{ Patient } & \multirow[t]{3}{*}{ statistics } \\
\hline & Willingness & Unwillingness & Uncertainty & & Willingness & UnwillingnessN(\%) & Uncertainty & \\
\hline & $\mathrm{N}(\%)$ & $\mathrm{N}(\%)$ & $N(\%)$ & & $\mathrm{N}(\%)$ & & $N(\%)$ & \\
\hline \multicolumn{9}{|l|}{ Area } \\
\hline suburban combination & $75(57.69)$ & $45(34.62)$ & 10(7.69) & $\chi^{2}=9.631$ & $43(40.19)$ & $22(20.56)$ & $42(39.25)$ & $\chi^{2}=3.46$ \\
\hline suburb & $487(61.65)$ & $230(29.11)$ & $73(9.24)$ & $P=0.047$ & $229(44.12)$ & $79(15.22)$ & $211(40.66)$ & $P=0.484$ \\
\hline urban & $422(54.88)$ & $279(36.28)$ & $68(8.84)$ & & $334(46.65)$ & 114(15.92) & $268(37.43)$ & \\
\hline \multicolumn{9}{|l|}{ Gender } \\
\hline male & 283(70.75) & $88(22.00)$ & $29(7.25)$ & $\chi^{2}=34.351$ & 197(40.79) & $84(17.39)$ & $202(41.82)$ & $\chi^{2}=5.824$ \\
\hline female & 701(54.38) & $466(36.15)$ & $122(9.46)$ & $P<0.001$ & $409(47.61)$ & 131(15.25) & $319(37.14)$ & $P=0.054$ \\
\hline \multicolumn{9}{|l|}{ Age } \\
\hline $18-30$ & 165(51.08) & 127(39.32) & $31(9.60)$ & $\chi^{2}=51.49$ & 154(53.10) & $32(11.03)$ & 104(35.86) & $x^{2}=27.52$ \\
\hline $31-45$ & $396(52.59)$ & 274(36.39) & $83(11.02)$ & $P<0.001$ & 296(44.31) & 108(16.17) & 264(39.52) & $P=0.001$ \\
\hline $46-60$ & $300(71.60)$ & $94(22.43)$ & $25(5.97)$ & & $79(42.25)$ & $26(13.90)$ & $82(43.85)$ & \\
\hline$>61$ & $123(63.40)$ & $59(30.41)$ & 12(6.19) & & 77(39.09) & $49(24.87)$ & $71(36.04)$ & \\
\hline \multicolumn{9}{|l|}{ Education } \\
\hline postgraduate & 239(70.29) & $83(24.41)$ & $18(5.30)$ & $\chi^{2}=53.755$ & $32(55.17)$ & $6(10.34)$ & $20(34.48)$ & $\chi^{2}=35.776$ \\
\hline undergraduate & 497(60.24) & 251(30.42) & 77(9.33) & $P<0.001$ & $340(52.23)$ & $91(13.98)$ & $220(33.79)$ & $P<0.001$ \\
\hline short-cycle Courses & $234(47.85)$ & $201(41.10)$ & $54(11.04)$ & & 111(34.15) & $60(18.46)$ & 154(47.38) & \\
\hline $\begin{array}{l}\text { short-cycle Courses and } \\
\text { Under }\end{array}$ & $14(40.00)$ & $19(54.29)$ & $2(5.71)$ & & 123(39.94) & $58(18.83)$ & $127(41.23)$ & \\
\hline \multicolumn{9}{|l|}{ Title*/Income ${ }^{\star \star}$} \\
\hline professor/> 10 & $15(68.18)$ & $6(27.27)$ & $1(4.55)$ & $\chi^{2}=75.525$ & $124(53.68)$ & $26(11.26)$ & $81(35.06)$ & $\chi^{2}=21.628$ \\
\hline associate professor /5.1-10 & $95(79.83)$ & $20(16.81)$ & $4(3.36)$ & $P<0.001$ & 199(44.42) & $74(16.52)$ & 175(39.06) & $P=0.006$ \\
\hline middle title /3.1-5 & $371(67.45)$ & $142(25.82)$ & $37(6.73)$ & & $121(40.74)$ & $48(16.16)$ & $128(43.10)$ & \\
\hline primary/1.1-3 & $396(52.17)$ & $277(36.50)$ & $86(11.33)$ & & $68(36.56)$ & $36(19.35)$ & $82(44.09)$ & \\
\hline no title/0-1 & 107(44.77) & $109(45.61)$ & $23(9.62)$ & & $94(52.22)$ & $31(17.22)$ & $55(30.56)$ & \\
\hline \multicolumn{9}{|l|}{ Departments } \\
\hline obstetrics-Gynecology & $270(58.19)$ & $160(34.48)$ & $34(7.33)$ & $\chi^{2}=20.194$ & 124(39.62) & $49(15.65)$ & $140(44.73)$ & $\chi^{2}=17.054$ \\
\hline orthopedics & 177(65.56) & 78(28.89) & 15(5.56) & $P=0.010$ & $128(48.67)$ & $43(16.35)$ & $92(34.98)$ & $P=0.030$ \\
\hline General surgery & $305(58.54)$ & $155(29.75)$ & 61(11.71) & & $200(46.30)$ & 74(17.13) & 158(36.57) & \\
\hline neurosurgery & $149(54.58)$ & 101(37.00) & 23(8.42) & & $99(51.03)$ & $32(16.49)$ & $63(32.47)$ & \\
\hline Cardio-Thoracic Surgery & $83(51.55)$ & $60(37.27)$ & 18(11.18) & & $55(39.29)$ & $17(12.14)$ & $68(48.57)$ & \\
\hline Total & 984(58.26) & $554(32.80)$ & $151(8.94)$ & & $606(45.16)$ & 215(16.02) & $521(38.82)$ & \\
\hline
\end{tabular}

* represent professional title in medical staff

**represent annual per capita income in patients

Table 5. The range of acceptable contributions for medical accident insurance between medical staff and patient 


\begin{tabular}{|c|c|c|c|c|c|c|c|c|c|c|}
\hline \multirow[t]{3}{*}{ parameter } & \multicolumn{5}{|c|}{ Medical staff } & \multirow[t]{2}{*}{ statistics } & \multicolumn{4}{|l|}{ Patient } \\
\hline & $\otimes 100$ & $100-200$ & $200-300$ & $300-500$ & $>500$ & & Harmony & General & Disharmony & Unclea \\
\hline & $\mathrm{N}(\%)$ & $N(\%)$ & $\mathrm{N}(\%)$ & $N(\%)$ & $\mathrm{N}(\%)$ & & $\mathrm{N}(\%)$ & $\mathrm{N}(\%)$ & $\mathrm{N}(\%)$ & $N(\%)$ \\
\hline \multicolumn{11}{|l|}{ Area } \\
\hline $\begin{array}{l}\text { suburban } \\
\text { combination }\end{array}$ & $33(27.50)$ & $36(30.00)$ & $24(20.00)$ & $15(12.50)$ & $12(10.00)$ & $\chi^{2}=4.447$ & $23(27.06)$ & 14(16.47) & 11(12.94) & $26(30$. \\
\hline suburb & 226(31.52) & 192(26.78) & 119(16.60) & 102(14.23) & 78(10.88) & $P=0.925$ & 134(30.45) & 116(26.36) & $65(14.77)$ & 70(15. \\
\hline urban & $214(30.53)$ & 194(27.67) & $109(15.55)$ & 114(16.26) & 70(9.99) & & 152(25.25) & 174(28.90) & 101(16.78) & $97(16$. \\
\hline \multicolumn{11}{|l|}{ Gender } \\
\hline male & $89(23.99)$ & $81(21.83)$ & 67(18.06) & 62(16.71) & 72(19.41) & $\chi^{2}=55.255$ & $110(27.57)$ & 109(27.32) & $57(14.29)$ & 71(17. \\
\hline female & $384(32.90)$ & $341(29.22)$ & 185(15.85) & $169(14.48)$ & $88(7.54)$ & $P<0.001$ & 199(27.34) & 195(26.79) & $120(16.48)$ & $122(1 \epsilon$ \\
\hline \multicolumn{11}{|l|}{ Age } \\
\hline $18-30$ & $90(30.82)$ & $86(29.45)$ & $43(14.73)$ & 44(15.07) & 29(9.93) & $\chi^{2}=12.794$ & $60(23.26)$ & 77(29.84) & $44(17.05)$ & $40(15$. \\
\hline $31-45$ & 201(30.00) & 183(27.31) & 111(16.57) & 102(15.22) & 73(10.90) & $P=0.618$ & 146(26.07) & 144(25.71) & $84(15.00)$ & $107(1 \mathrm{~s}$ \\
\hline $46-60$ & 125(31.73) & 104(26.40) & $65(16.50)$ & $60(15.23)$ & $40(10.15)$ & & $52(32.30)$ & 44(27.33) & 28(17.39) & $19(11$. \\
\hline$>61$ & $57(31.32)$ & $49(26.92)$ & $33(18.13)$ & $25(13.74)$ & 18(9.89) & & $51(34.46)$ & $39(26.35)$ & 21(14.19) & $27(18$. \\
\hline \multicolumn{11}{|l|}{ Education } \\
\hline postgraduate & $71(22.05)$ & $85(26.40)$ & $53(16.46)$ & $58(18.01)$ & $55(17.08)$ & $\chi^{2}=58.253$ & 14(26.92) & $7(13.46)$ & $9(17.31)$ & $9(17.3$ \\
\hline undergraduate & $224(29.95)$ & 205(27.41) & 138(18.45) & 111(14.84) & 70(9.36) & $P<0.001$ & $125(22.32)$ & $160(28.57)$ & 89(15.89) & $100(1 ;$ \\
\hline $\begin{array}{l}\text { short-cycle } \\
\text { Courses }\end{array}$ & 166(38.16) & $124(28.51)$ & $58(13.33)$ & $56(12.87)$ & 31(7.13) & & $83(31.32)$ & $70(26.42)$ & $44(16.60)$ & $47(17$. \\
\hline $\begin{array}{l}\text { short-cycle } \\
\text { Courses and } \\
\text { Under }\end{array}$ & 12(36.36) & $8(24.24)$ & $3(9.09)$ & 6(18.18) & $4(12.12)$ & & $87(34.80)$ & $67(26.80)$ & $35(14.00)$ & $37(14$. \\
\hline \multicolumn{11}{|l|}{ Title*/Income ${ }^{\star \star}$} \\
\hline professor/> 10 & $5(23.81)$ & $5(23.81)$ & 4(19.05) & 4(19.05) & $3(14.29)$ & $x^{2}=35.645$ & $40(19.51)$ & 45(21.95) & $35(17.07)$ & $44(21$. \\
\hline $\begin{array}{l}\text { associate } \\
\text { professor /5.1- } \\
10\end{array}$ & $25(21.74)$ & $34(29.57)$ & $21(18.26)$ & 18(15.65) & 17(14.78) & $P=0.017$ & $97(25.94)$ & $98(26.20)$ & $53(14.17)$ & $78(20$. \\
\hline $\begin{array}{l}\text { middle title } \\
\text { /3.1-5 }\end{array}$ & 159(30.99) & 132(25.73) & $89(17.35)$ & $75(14.62)$ & $58(11.31)$ & & 74(29.72) & 74(29.72) & $38(15.26)$ & $36(14$. \\
\hline primary/1.1-3 & 231(34.32) & 190(28.23) & 104(15.45) & $90(13.37)$ & $58(8.62)$ & & 49(32.67) & $43(28.67)$ & $24(16.00)$ & $18(12$. \\
\hline no title/0-1 & $53(24.54)$ & $61(28.24)$ & $34(15.74)$ & $44(20.37)$ & $24(11.11)$ & & 49(32.89) & $44(29.53)$ & 27(18.12) & $17(11$. \\
\hline \multicolumn{11}{|l|}{ Departments } \\
\hline $\begin{array}{l}\text { obstetrics- } \\
\text { Gynecology }\end{array}$ & 141(32.79) & $126(29.30)$ & $59(13.72)$ & $65(15.12)$ & $39(9.07)$ & $\chi^{2}=26.378$ & $65(24.62)$ & $80(30.30)$ & $40(15.15)$ & $42(15$. \\
\hline orthopedics & $72(28.24)$ & $65(25.49)$ & 47(18.43) & $38(14.90)$ & $33(12.94)$ & $P=0.154$ & $60(27.27)$ & $56(25.45)$ & $35(15.91)$ & $40(18$. \\
\hline General surgery & 144(31.30) & 117(25.43) & 80(17.39) & 72(15.65) & $47(10.22)$ & & $98(27.37)$ & $91(25.42)$ & 63(17.60) & 61(17. \\
\hline neurosurgery & $69(27.60)$ & $80(32.00)$ & $42(16.80)$ & $30(12.00)$ & $29(11.60)$ & & $56(34.57)$ & $40(24.69)$ & $22(13.58)$ & 23(14. \\
\hline $\begin{array}{l}\text { Cardio- } \\
\text { Thoracic } \\
\text { Surgery }\end{array}$ & 47(32.87) & $34(23.78)$ & 24(16.78) & 26(18.18) & 12(8.39) & & $30(24.39)$ & $37(30.08)$ & 17(13.82) & $27(21$. \\
\hline Total & $473(30.75)$ & $422(27.44)$ & 252(16.38) & 231(15.02) & $160(10.40)$ & & $309(27.42)$ & $304(26.97)$ & 177(15.71) & 193(1; \\
\hline
\end{tabular}

* represent professional title in medical staff

**represent annual per capita income in patients

Figures 


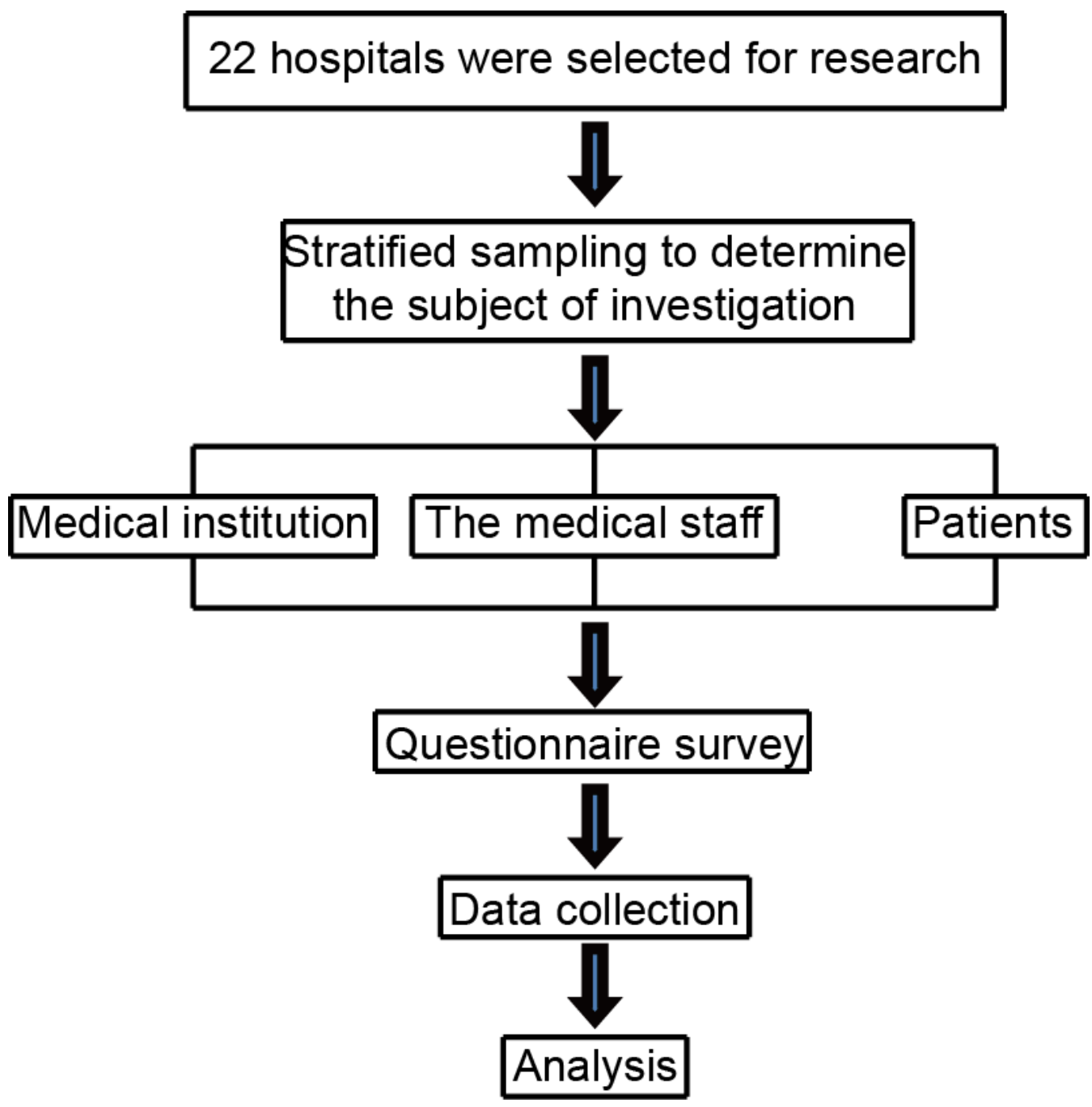

Figure 1

Flow chart of respondents' selection in this questionnaire survey.

A Happened

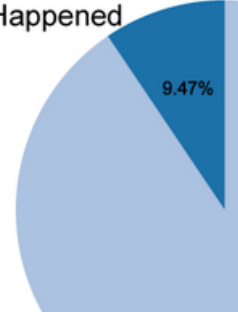

$90.53 \%$

Not happened
Happened
$6.39 \%$

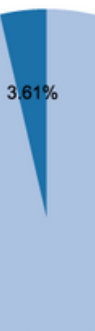

$96.39 \%$

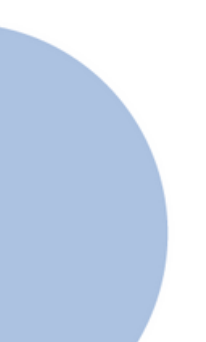

Not happened
C

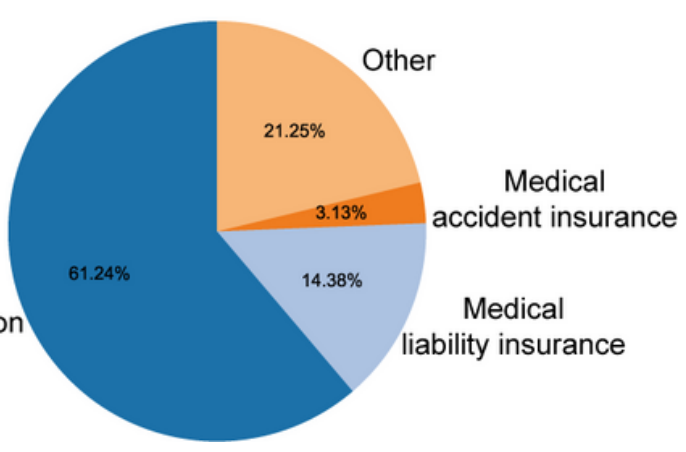

Figure 2

The occurrence frequency of medical malpractice and its compensation method. 

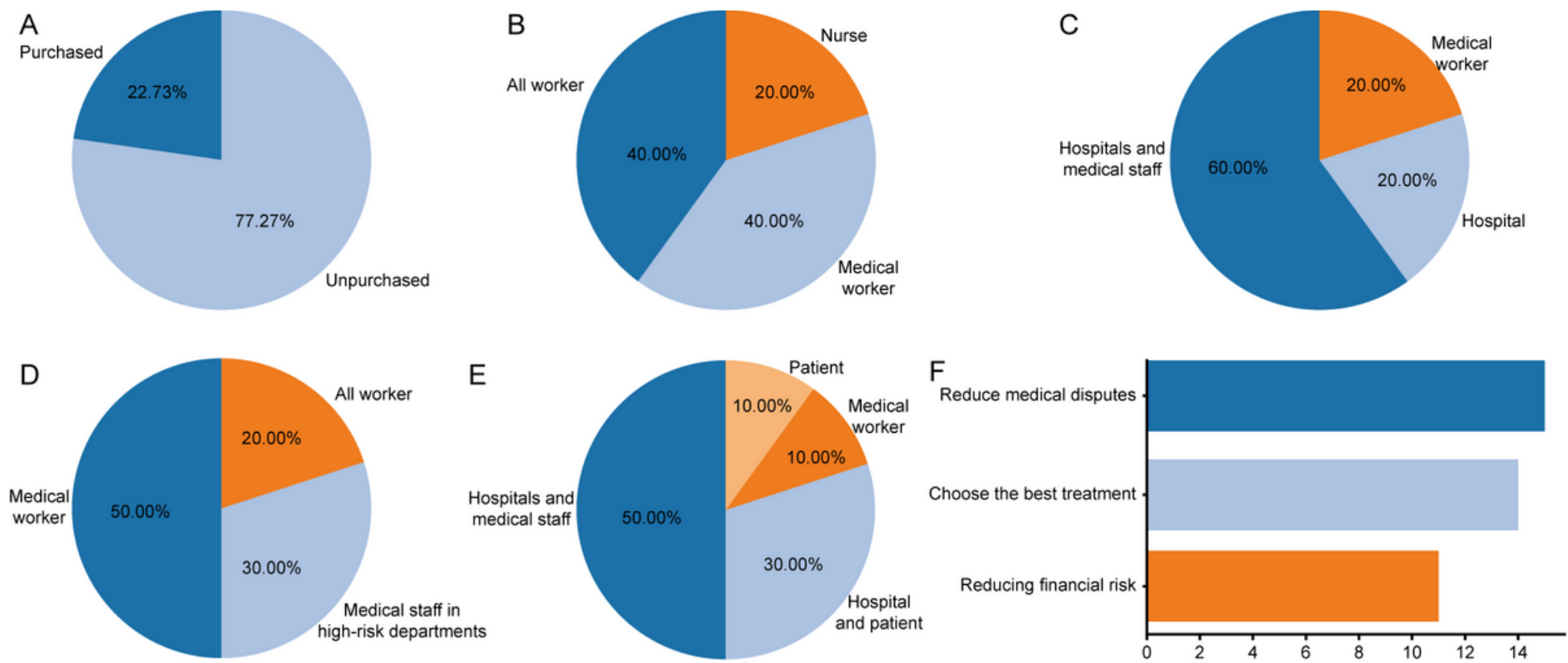

Figure 3

The purchase status quo of medical accident insurance.

A Cognition of doctor-patient relationship

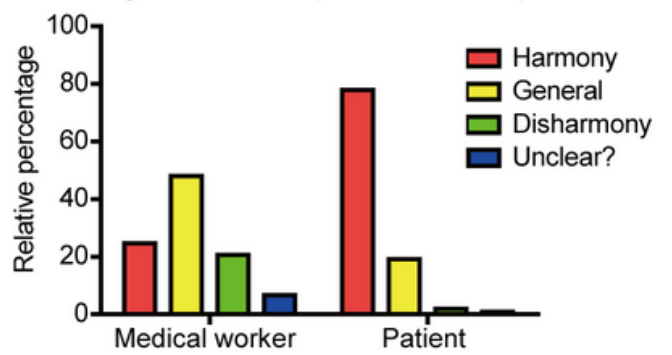

D Reasons for Unwillingness

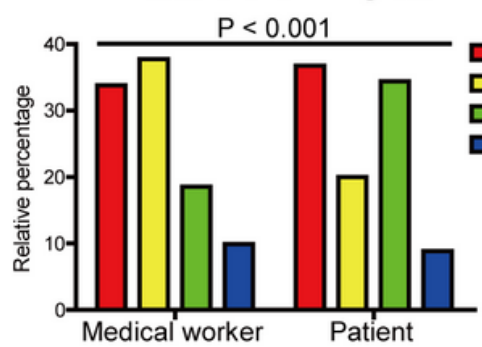

$\square$ No sense of purchase $\square$ Little benefit $\square$ High-cost/Unkown of purchase way Other

Figure 4

The cognition of medical accident insurance and purchase intention
B Cognition of medical accident insurance

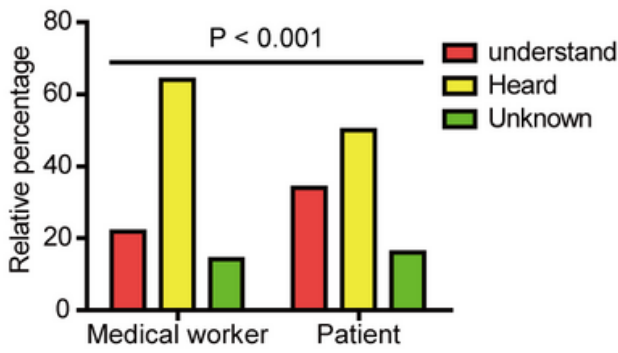

C Purchase Intention

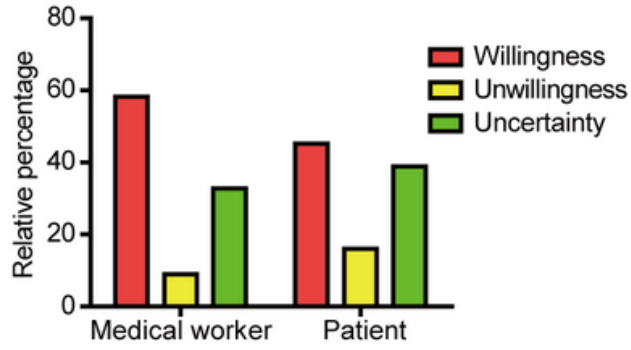

E Purchase insurance cost

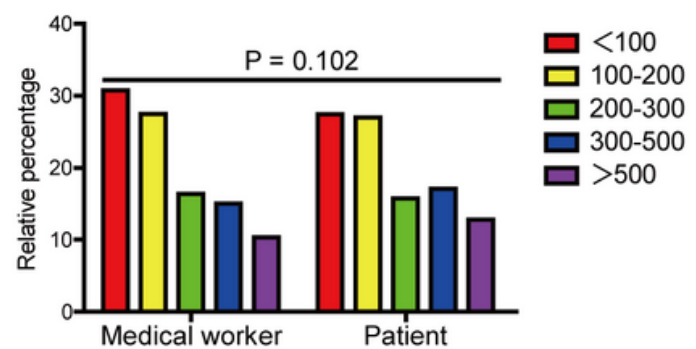

